\title{
Mass mortalities associated with a virus disease in Japanese pearl oysters Pinctada fucata martensii
}

\author{
Teruo Miyazaki*, Kuniko Goto, Tatsuya Kobayashi, Tetsushi Kageyama, Masato Miyata
}

Faculty of Bioresources, Mie University, 1515 Kamihama, Tsu, Mie 514-8509, Japan

\begin{abstract}
The annual mortality of cultured Japanese pearl oysters Pinctada fucata martensii in all western regions of Japan was over 400 million in both 1996 and 1997. The main pathological signs of the diseased oysters were atrophy in the adductor muscle, the mantle lobe and the body accompanied by a yellowish to brown coloration. Histological studies revealed necrosis and degeneration of muscle fibers of the adductor, pallial and foot musculatures as well as the cardiac muscle. Electron microscopy revealed the presence of small round virions approximately $30 \mathrm{~nm}$ in diameter within intrasarcoplasmic inclusion bodies in necrotized muscle fibers of the adductor and pallial musculatures, and the heart. The causative virus was isolated and cultured in EK-1 (eel kidney) and EPC (epithelioma papilosum cyprini) fish cell lines. Marked mortalities occurred in pearl oysters that had been experimentally inoculated with the cultured virus; these oyster displayed the same pathological signs of the disease as oysters in natural infections. These resuits indicate that a previously undescribed virus caused the mass mortalities in cultured pearl oysters.
\end{abstract}

KEY WORDS: New virus disease - Japanese pearl oyster - Mass mortality - Virus in muscle fiber

\section{INTRODUCTION}

Mass mortalities of the cultured Japanese pearl oyster Pinctada fucata martensii (hereafter akoya oyster) have occurred in juvenile, mother and operated oysters in western regions of Japan since 1994. In 1996 and 1997, the annual mortality of akoya oysters in all the western regions was over 400 million oysters, which was over $50 \%$ of the oysters in production, without any obvious problems with seawater quality such as red tides. The total economic loss was over 30 billion Japanese yen. This was due not only to mortality, but also to the decreased quality of the pearls produced, which had deformities, dark spots, dark coloration throughout, and/or a poorer quality luster due to the poor formation of the pearl layer. The mortalities have raised fears not only of a shortage of high quality pearls, which are sold all over the world, but also of extinction of the subspecies martensii. The present study was conducted to investigate the cause of the mass mortality of akoya oysters. Here, we present the

•E-mail: miyazaki@bio.mie-u.ac.jp results of histopathological and electron microscopic studies, and report the isolation and culture of the causative virus. The results of infectivity experiments are also reported.

\section{MATERIALS AND METHODS}

Akoya oysters. About 2002 -yr-old mother oysters were randomly collected from different farming areas that were experiencing mass mortalities from July to October in 1997. Twenty oysters, both diseased and healthy, were collected at each sampling. Moreover, in order to investigate akoya oysters in the season during which mass mortality did not occur, 20 mother oysters were randomly collected from cold water which was at a temperature of around $16^{\circ} \mathrm{C}$ in mid-November 1997. Twenty juvenile oysters and 53 mother oysters were also randomly collected from cold water at a temperature of around 17 to $18^{\circ} \mathrm{C}$ in January and March 1998. The above farming areas were in the Pacific and the Japan Sea coasts of the Honshu, Shikoku and Kyushu islands. In addition, a total of 30 healthy mother oysters 
were collected from 2 regions of Kyushu island in May 1997, before the season during which mass mortality occurred.

Monitoring of mass mortality. One hundred mother oysters were randomly selected from a group of cultured oysters and placed within net cages near other cultured oysters in a farming area on Shikoku island. The weekly mortality and the water temperature at a depth of $1 \mathrm{~m}$ were checked from the end of July to the end of October in 1997.

Histopathological and electron microscopic examinations. All sampled oysters, including both diseased and healthy ones, in all experimental groups were dissected after external and internal examinations. A piece of the adductor muscle, the lips of the mantle lobe and other visceral organs were fixed in $10 \%$ phosphate buffered formalin for histological studies. The fixed tissues were prepared according to standard techniques and stained with hematoxylin \& eosin (H\&E), Azan, Giemsa, Periodic Acid Schiff (PAS) reaction. In addition, the Feulgen reaction was used for detecting DNA. Half of the remaining adductor muscle and mantle lobe were fixed in $70 \%$ Karnovsky solution, postfixed in $1 \%$ OsO4 and processed for electron microscopy (EM) according to standard techniques. In this study, some thin sections of prefixed tissues were treated within $1 \%$ amylase solution $(\mathrm{pH} 8.0)$ at $36^{\circ} \mathrm{C}$ for $24 \mathrm{~h}$ because the virus particles resembled in size glycogen granules inside the muscle fibers. This treatment was effective in removing glycogen granules and thus revealing the virus particles within the muscle fibers by EM.

Cell lines and virus culture. EK-1 (eel kidney; Chen et al. 1982) and EPC (epithelioma papilosum cyprini; Tomasec \& Fijan 1971) cells were used for the virus isolation and culture. The EK-1 cells were cultured with Leibovitz's L-15 medium (L-15) adding 10\% fetal bovine serum (FBS). EPC cells were cultured with Eagle's minimum essential medium (MEM) with 10\% FBS. For primary virus isolation, either half of the adductor muscle or a pool consisting of a piece of the adductor muscle and a piece of the mantle lobe was taken from diseased or unaffected oysters, and homogenized in culture medium (L-15 or MEM). Filtrates of the homogenate ( $450 \mathrm{~nm}$ filter) were inoculated into EK-1 and EPC cells at $0.5 \mathrm{ml}$ in $5 \mathrm{ml}$ of the culture medium, which contained $2 \% \mathrm{FBS}$ in a $25 \mathrm{~cm}^{2}$ flask. Inoculated cells were incubated at $25^{\circ} \mathrm{C}$. Because the normal MEM medium was rather ineffective in the primary isolation and culture of the causative virus, and because, as mentioned below, the infected akoya oysters showed an abnormally accelerated glycogen metabolism, $0.2 \%$ glucose was supplemented for virus cultivation with EPC cells. Glucose supplement was effective in primary isolation. However, primary isola- tion with serially diluted filtrates resulted in failure when we used a 96-well plate (micro-titer plate) because, for an unknown reason, the virus never grew in a small volume of medium inside small wells. Therefore, virus titration was impossible. A serial culture of the isolate succeeded only in a 12-well plate using EPC cells. Because of this, for infectivity examinations, viral levels of inocula were checked only with EPC cells in a 12-well plate. Virus isolation was performed on randomly selected oysters from diseased groups and unaffected groups. Their disease status was confirmed histopathologically. Moreover, in order to verify isolation and culture of virus, EM examinations including negative stain were performed in accordance with standard techniques.

Infectivity experiments. Three experiments were performed in the winter season because it was the offseason with respect to mass mortality and because the akoya oysters obtained were survivors or had been spared viral infection in the previous summer season. Healthy oysters had well-formed valves and wellextended mantle lobe lips, and quickly reacted to a light touch on the lip of the mantle lobe by shutting their valves. For infectivity experiments, apparently healthy oysters were carefully selected from groups of either wild or cultured oysters ( 2 to 3 yr old) in order to avoid the affected oysters. Inocula $(0.5 \mathrm{ml})$ containing 5 virus isolates (E-1, E-2, E-3, F-1 and M-1) were injected into the mantle lobe lips of experimental oysters. These virus isolates were obtained from different diseased oysters which were collected from 3 different farming areas. The virus levels of inocula were $10^{5}$ to $10^{6} \mathrm{ml}^{-1}$. The corresponding control groups (C-1 for E-1-2, C-2 for E-3 and F-1, and C-3 for M-1) were injected with medium only, in the same way as experimental oysters. Each group comprised 7 to 10 oysters. After the injection, each group was placed in aquaria with a flowthrough system using artificial seawater at $25^{\circ} \mathrm{C}$. Dead and moribund oysters were removed and their tissues were prepared for histopathological and EM examination. Also, virus was re-isolated from the adductor muscle and heart in the same way as from diseased oysters in the natural outbreak.

\section{RESULTS}

\section{Monitoring of mass mortality}

During the monitoring period weekly mortalities were high when the water temperature was $25^{\circ} \mathrm{C}$ or higher and mortality decreased markedly when the water temperature was lower than $25^{\circ} \mathrm{C}$ (Fig. 1). Cumulative mortality had reached $43 \%$ by the end of the 3 mo long monitored period. 


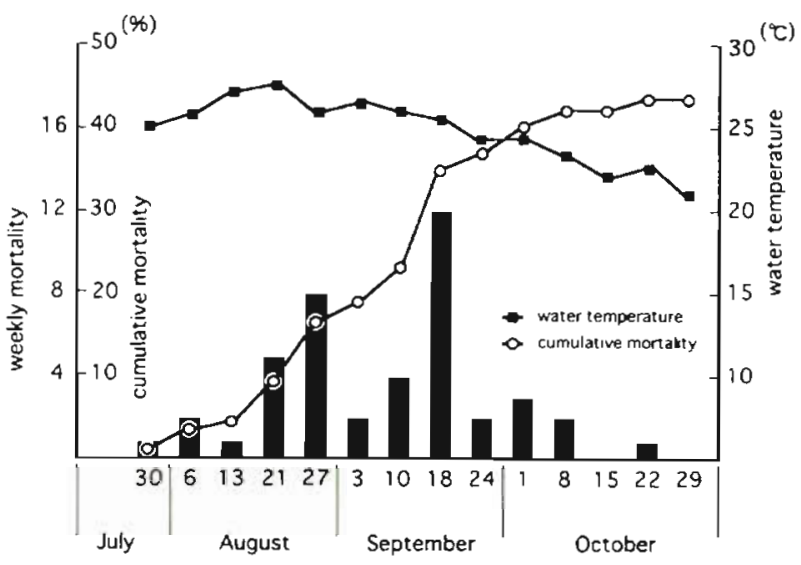

Fig. 1. Pinctada fucata martensii. Monitored mortality of 100 akoya oysters in Ehime Prefecture in 1997. Weekly mortality was marked when the water temperature was $25^{\circ} \mathrm{C}$ or higher. Cumulative mortality reached $43 \%$ by the end of the monitored period. Histogram: weekly mortality

\section{Gross pathology in natural outbreaks}

Examinations of affected akoya oysters from the natural outbreak revealed the following: the edge of diseased akoya oyster valves displayed poor growth; there were functional disturbances in the opening and shutting of valves, and a sluggish shutting of valves when the oyster was lightly touched on the lip of the mantle lobe. Views of dissected oysters showed that, as compared to unaffected or healthy oysters, which had milky-colored adductor muscle and mantle lobes covering their fattened bodies, diseased oysters showed pathological signs, such as atrophy in the adductor muscle, lips of the mantle lobe and the body, and transparent mantle lobes due to a markedly decreased number of nutrient-storing cells underlying the mantle lobe. Moreover, yellowish to brown coloration occurred in the adductor muscle and the mantle lobe. The dark coloration of the adductor muscle tended to occur during the period of higher water temperatures in summer, while the light coloration was mostly observed during the periods when the water temperature was under $20^{\circ} \mathrm{C}$.

\section{Histopathology and electron microscopy}

Because there have been no systemic histological studies of akoya oysters, we describe here the histology of healthy oysters for comparison. The adductor muscle of healthy oysters consisted of many fasciculi in a parallel array that were enclosed within the perimysium of the fibrous tissue. The adductor muscle had fasciculi consisting of thick, smooth muscle fibers, most of which were wavy and densely arrrayed (Fig. 2A), except for an array of fasciculi beside the intestine which had straight muscle fibers. Because akoya oysters store glycogen in the adductor muscle fibers, they reacted strongly to PAS. Diseased oysters, on the other hand, displayed extensive muscular damage, as described below. The affected adductor muscle displayed necrosis, atrophy, swelling and vacuolization of the muscle fibers (Fig. 2B-D). The necrotized muscle fibers usually showed karyopyknosis, karyorrhexis and marginal hyperchromatosis, and had been partially destroyed and infiltrated by numerous hemocytes. In severe cases, there was extensive damage to the adductor muscle, and the perimysium also contained many hemocytes and necrotized cells. The severity of the muscular damage corresponded with the severity of the atrophic change rather than the dark coloration of the adductor muscle. The PAS reaction revealed decreased levels of glycogen in the severely damaged muscle fibers. These damaged muscle fibers never showed Feulgen-positive inclusions, which indicated that virions of the putative virus had RNA.

In healthy oysters, the foot musculature consisted of many fasciculi that crossed over each other and that were made up of thick muscle fibers (Fig. 3A). In diseased oysters, the muscle fibers were markedly atrophied and necrotized and partly destroyed followed by infiltration of numerous hemocyte and fibrous tissues (Fig. 3B).

In the mantle lobe of the healthy oysters, the central area had thick muscle fibers lying parallel under the connective tissues while the lip had musculature consisting of spindle-shaped muscle fibers that crossed over each other in the connective tissue (Fig. $3 \mathrm{C}$ ). The connective tissue contained hemocytes between the fibers and sinuses. In diseased oysters, muscle fibers were markedly atrophied and necrotized. Necrotized fibers were destroyed and had been infiltrated by fibrous tissue and hemocytes (Fig. 3D). The connective tissue sometimes showed necrotic cells, and the number of hemocytes was variable between the fibers and sinuses.

In the heart of healthy oysters, the cardiac muscle had a dense, spongiform structure of thick cardiac muscle fibers (Fig. 4A), whereas in diseased oysters, the cardiac muscle fibers showed atrophy, vacuolization and necrosis, which subsequently resulted in moderate or marked destruction and hemocyte infiltration (Fig. 4B). Moreover, in diseased oysters, the muscular tissue in the gills was often necrotized and showed hemocyte infiltration, but the respiratory epithelia were not affected.

In the season during which mass mortality occurred, around 40 to $80 \%$ of the oysters in each sampling group displayed these types of muscular damage. This high level of occurrence was positively correlated with 

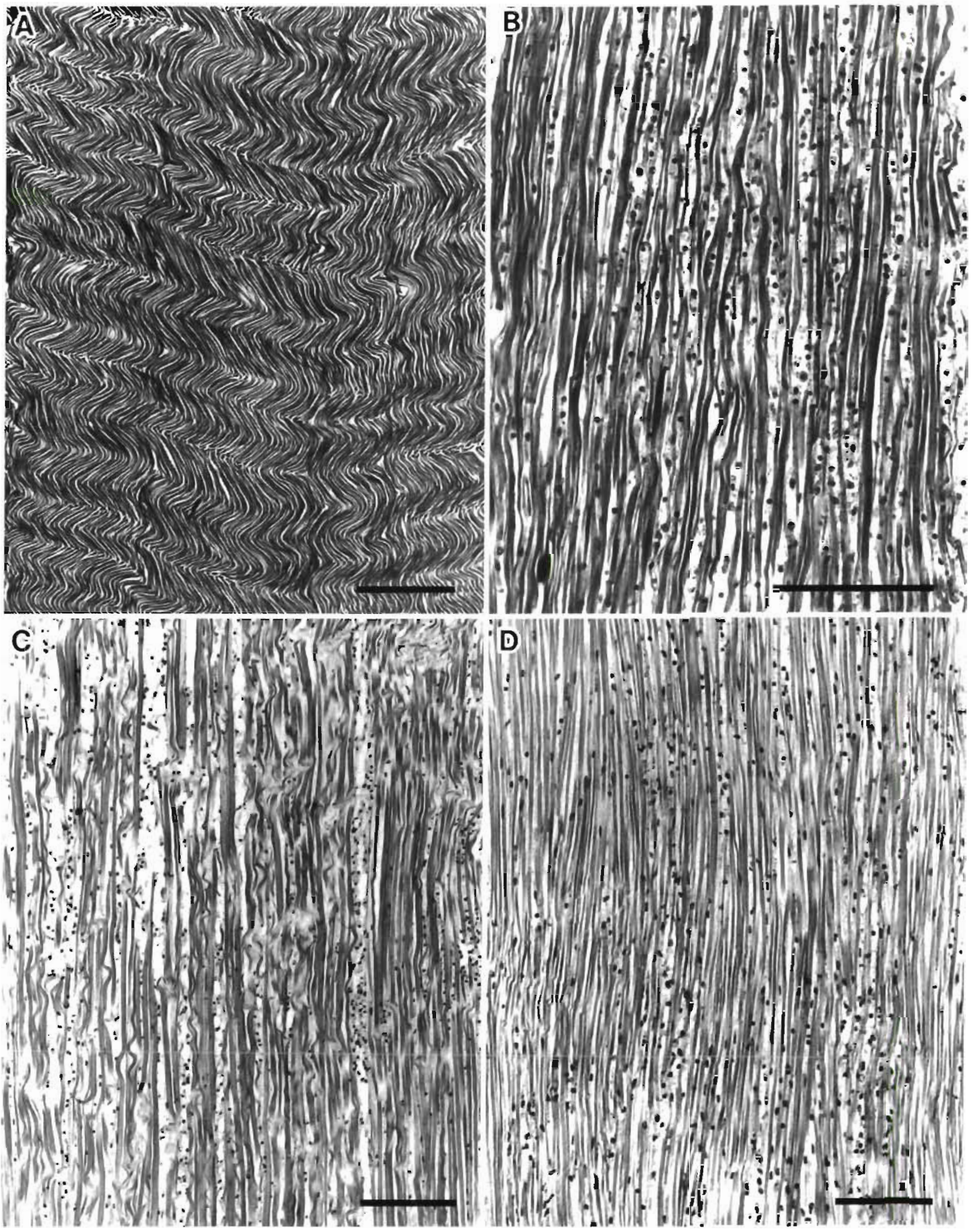

Fig. 2. Pinctada fucata martensii. (A) Adductor muscle of healthy akoya oyster consisting of a dense array of thick, smooth wavy muscle fibers. Azan. (B-D) Adductor muscle of diseased oysters. (B) Muscle fibers have become very straight and were extensively swollen and necrotized. Necrotized fibers show partial liquefaction and hemocyte infiltration. Azan. (C) Affected muscle fibers are straight, swollen and necrotized. H\&E. (D) Muscle fibers are straight, atrophied and necrotized with hemocyte 


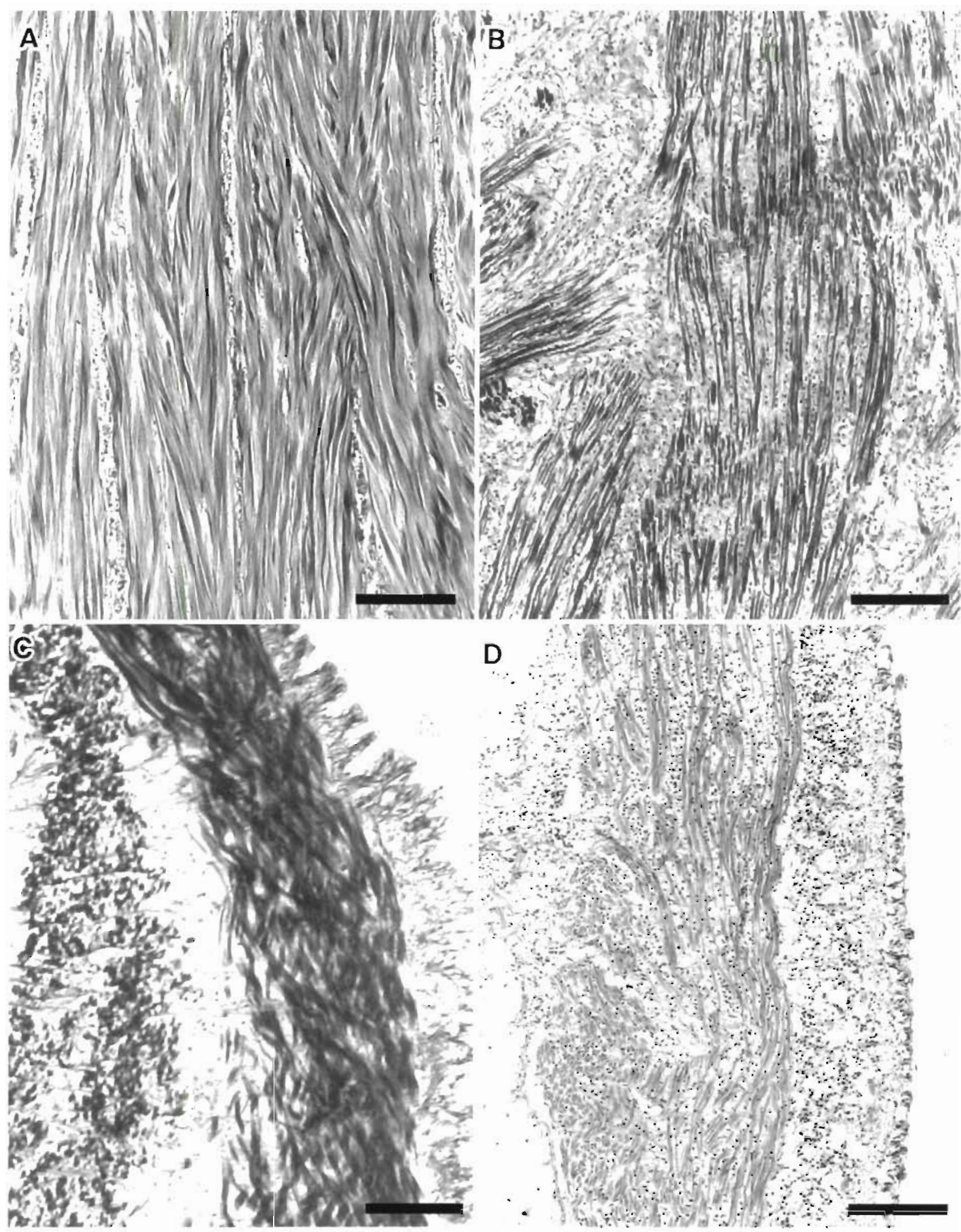

Fig. 3. Pinctada fucata martensii. (A) Normal foot musculature consists of tasciculı which cross over each other and are made up of straight, thick muscle fibers. H\&E. (B) In the infected foot musculature, muscle fibers are markedly atrophied and necrotized Necrotized fibers have partially disappeared and have been replaced by fibrous tıssue containung hemocytes Azan. (C) Normal pallial musculature consists of thick muscle fibers which cross each other in the connective tissue. Azan. (D) Infected pallial musculature displays necrotized and atrophied muscle fibers. Necrotized fibers have partially been destroyed and infiltrated by fibrous tissue and hemocytes. Hemocyte infiltration is also marked in the connective tissue Azan Scale bars $=100 \mu \mathrm{m}$ 


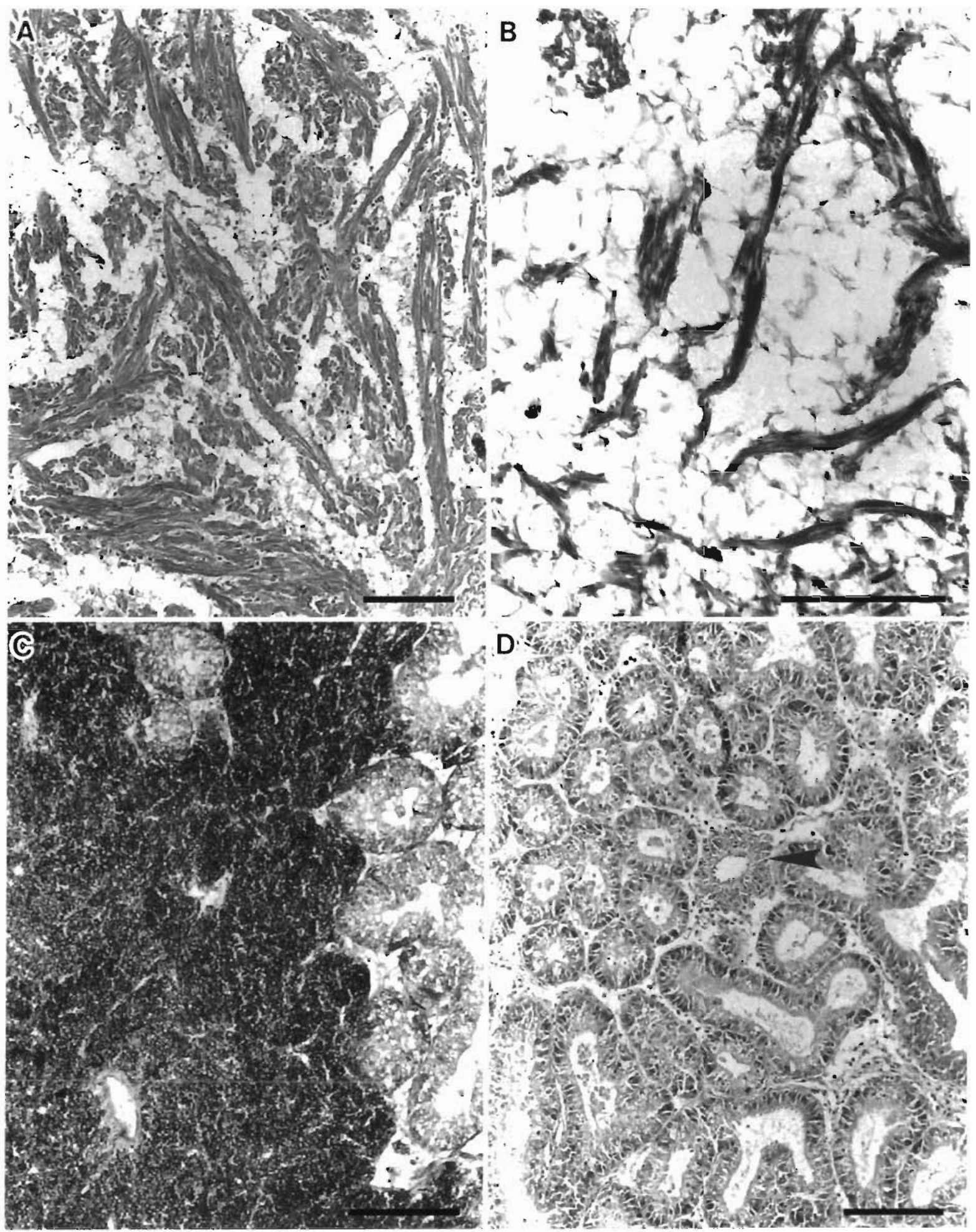

Fig. 4. Pinctada fucata martensii. (A) Normal cardiac muscle which has a dense spongiform structure consisting of thick cardiac muscle fibers. H\&E. (B) The infected cardiac muscle is so severely damaged that it has disappeared. Azan. (C) Normal digestive caeca and mass of nutrient-storing (NS) cells. Epithelia of digestive caeca have well-expanded cells with good phagosome formation. A large number of NS cells containing granules of glycogen and protein are located around vessels among the digestive caeca. PAS. (D) In diseased oysters, epithelia of digestive caeca have cells with reduced phagosome and expanded lumens. A small number of NS cells having a reduced amount of glycogen and fewer protein granules remain around the vessels (arrowhead). H\&E. Scale bars $=100 \mu \mathrm{m}$ 
high water temperature. However, in a small number of mother oysters which were sampled in late October and during the cold water season, muscular lesions displayed production of fibrous tissue around the necrotized muscle fibers that indicated healing, whereas regenerating muscle fibers did not appear. In juvenile oysters that were sampled in the cold water, $80 \%$, surprisingly, had muscular damage.

The visceral mass contained the stomach, the digestive caeca, which had blind tubules, the intestine, the gonad and the kidney. In healthy oysters, the tubular epithelia of digestive caeca had well-expanded cells with good phagosome formations, protein granules and yellow pigments derived from chlorophyll (Fig. 4C). A large number of nutrient-storing cells (hereafter NS cells) full of granules of glycogen and protein were located around vessels in the fibrous connective tissue surrounding tubules of the digestive caeca (Fig. 4D). The connective tissue contained many hemocytes. NS cells were also located in the gonadal tissue. In contrast, in diseased oysters, epithelial cells of digestive caeca had fewer phagosomes and less absorbed matter, causing the epithelia to become flat and the lumen to enlarge (Fig. 4D). NS cells had fewer protein granules and less glycogen in the cytoplasm. NS cells mostly disappeared when the body was severely atrophied (Fig, 4D). The connective tissue was extensively edematous and showed necrotic cells and markedly fewer of hemocytes. The kidney and gonad appeared to be unaffected.

In EM of in healthy akoya oysters, muscle fibers usually had rather thick myofibrils and an extensive sarcoplasm which contained abundant fine glycogen granules, mitochondria and reticula (Fig. 5A). In diseased oysters, EM revealed formations of membranous inclusion bodies within electron-dense debris inside the sarcoplasm of necrotized muscle fibers in the adductor muscle (Fig. 5B-D) and pallial musculature. These inclusion bodies contained many small round, viral particles with a diameter of 25 to $33 \mathrm{~nm}$ and no envelope. These infected muscle fibers had thinned or markedly fragmented myofibrils. The sarcoplasm showed vacuolization, mitochondria with destroyed cristae, expanded reticula and almost no glycogen granules (Fig. 5B). The muscle fibers that were slightly affected usually displayed thinned myofibrils and densely aggregated glycogen granules inside the vacuolized sarcoplasm.

\section{Virus isolation and culture}

When inoculated, EK-1 and EPC cells were incubated at $25^{\circ} \mathrm{C}$ for primary isolation, they began to display a cytopathic effect (CPE), showing karyopyknosis and vacuole formation in the cytoplasm. Infected cells became round in shape and then lifted off the bottom surface of the flask within 7 to $14 \mathrm{~d}$. CPE was completed in 14 to $30 \mathrm{~d}$. In EPC cell cultivation that was supplemented with $0.2 \%$ glucose, the $\mathrm{pH}$ of the medium dropped to 6.1 at the same time CPE developed. The second and third serial cultivations of the isolated virus were successful using a $25 \mathrm{~cm}^{2}$ flask or a 12 -well plate. All attempts at titration, purification and virological examinations resulted in failure when micro-titer plates were used.

This virus was successfully isolated from a total of 42 of 55 diseased mother oysters and, as expected, no virus was isolated from 13 unaffected mother oysters which were examined from early August to late October. The same virus was also isolated from 22 of 25 diseased mother oysters, whereas no virus was isolated from 36 unaffected mother oysters which were collected from the cold water. The failure to isolate virus from some of the diseased oysters might be due to the difficulty of virus cultivation or to healing of infected lesions. The virus was also isolated from 4 of 9 diseased juveniles oysters that were collected in January 1998.

In inoculated cells, EM revealed intracytoplasmic multiplication of many virions showing the same shape and size as those found in the necrotic muscle fibers of affected oysters. Virions formed beside vacuoles and within electron-dense areas in EK-1 cells (Fig. 6A) or within electron-dense bodies that looked like inclusions in EPC cells. For purification of virions, the cultivate was centrifuged at $100000 \times g$ for $2 \mathrm{~h}$. Then, the obtained supernatant was mixed with polyethylene glycol and centrifuged again at $160000 \times g$ for $2 \mathrm{~h}$. The obtained sediment contained virions which were round and had diameters of 25 to $30 \mathrm{~nm}$ (Fig. 6B), which was also the case for virions observed in infected cells.

\section{Mortality and histopathology in experimentally diseased akoya oysters}

Inoculated akoya oysters displayed difficulty in opening their valves and a sluggish reaction to a light touch on the lip of the mantle lobe at about $7 \mathrm{~d}$ after inoculation. They also kept their valves widely opened just before death. Mortality occurred after $10 \mathrm{~d}$ and was 50 to $100 \%$ during the experimental period (Fig. 7). The virus was isolated again from the adductor muscle and heart of moribund and dead oysters that were examined. The moribund oysters, like those in the natural outbreak, mostly displayed an atrophied adductor muscle, atrophied mantle lobe lips, foot and body which was covered with transparent mantle lobes (Fig. 8A). The adductor muscle and the body of these oysters sometimes showed a yellowish to brown 


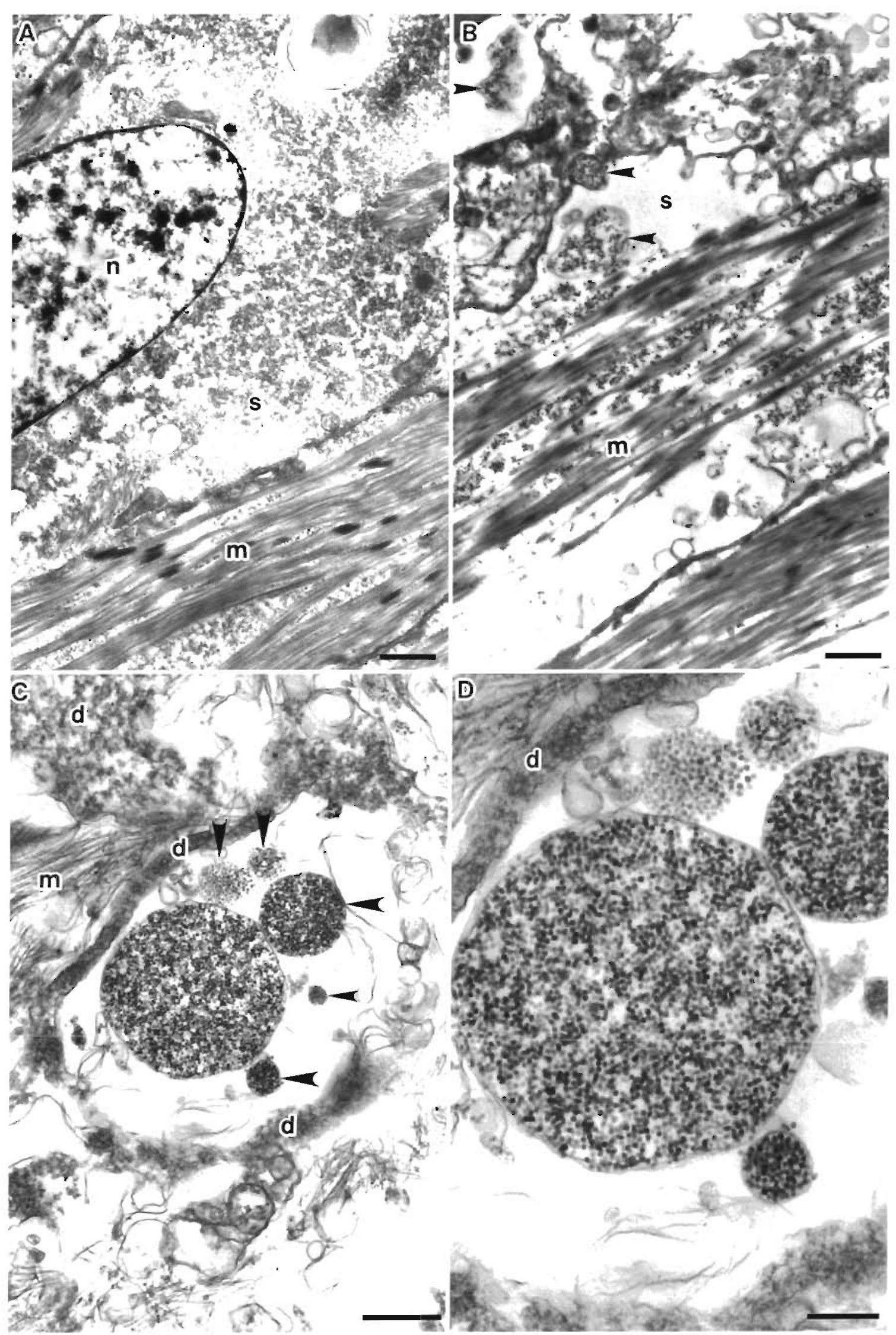


Fig. 5. Pinctada fucata martensii. (A) Electron micrograph of a normal muscle fiber in the adductor Abundant, fine glycogen granules freely present in the sarcoplasm ( $\mathrm{s}$ ) and between thick myofibrils ( $\mathrm{m}$ ). $\mathrm{n}=$ nucleus. Scale bar $=100 \mathrm{~nm}$. (B) In an infected muscle fiber of the adductor muscle, membranous inclusion bodies including virus particles (arrowheads) are formed in the vacuolized sarcoplasm. Glycogen granules are markedly fewer in the sarcoplasm (s) and between fragmented myofibrils (m). Scale bar = $100 \mathrm{~nm}$. (C) In a markedly necrotized muscle fiber, virions multiply in various-sized inclusion bodies (arrowheads) surrounded by amorphous debris (d) in the vacuolized sarcoplasm. Myofibrils (m) are markedly fragmented. Amylase-treated specimen. Scale bar $=700 \mathrm{~nm}$. (D) A high power view of (C). Small round, virions multiply in membranous inclusion bodies Scale bar $=300 \mathrm{~nm}$

coloration. In histological examinations, these oysters showed the same extensive necrotic and atrophic changes in their muscle fibers in the adductor (Fig. 8B), pallial, foot, gill and cardiac musculatures as were found in the natural outbreak. EM also revealed virus multiplication in the necrotized muscle fibers of the adductor muscle (Fig. 8C) and heart, which was same as was observed in the natural outbreak. The number of NS cells had decreased markedly or were almost entirely absent. Oysters that had cardiac necrosis usually died early in the experiments. In these oysters, NS cells did not have an unusually low amount of nutrients and were not fewer in number. The corresponding control groups usually opened their valves to circulate water inside the pallial cavity and attached their valves with the byssus to the walls of the aquarium. One control group had 1 dead oyster, but the other 2 control groups had no mortality during the experimental periods. The control oysters were all dissected at the end of experiment. In spite of their longer-term fast, they remained in fairly good condi- tion (Fig. 8A). In histological examinations, necrotic change was never observed in the muscular tissue Compared with moribund oysters, control oysters usually showed a rather moderate decrease in the amount of glycogen in the NS cells. No virus was isolated from their adductor muscle. These results from the control oyster groups proved that healthy oysters had been selected for the infectivity experiments.

\section{DISCUSSION}

In this study, a virus was isolated and cultured within fish cell lines. The virus was isolated from diseased akoya oysters that experienced mass mortalities in 4 different farming regions in western Japan. Oysters artificially infected with representative isolates of the virus had exactly the same pathogenicity and the same histopathological signs and marked mortalities as did in oysters in the natural outbreak. The virus was isolated again from the infected musculature of the
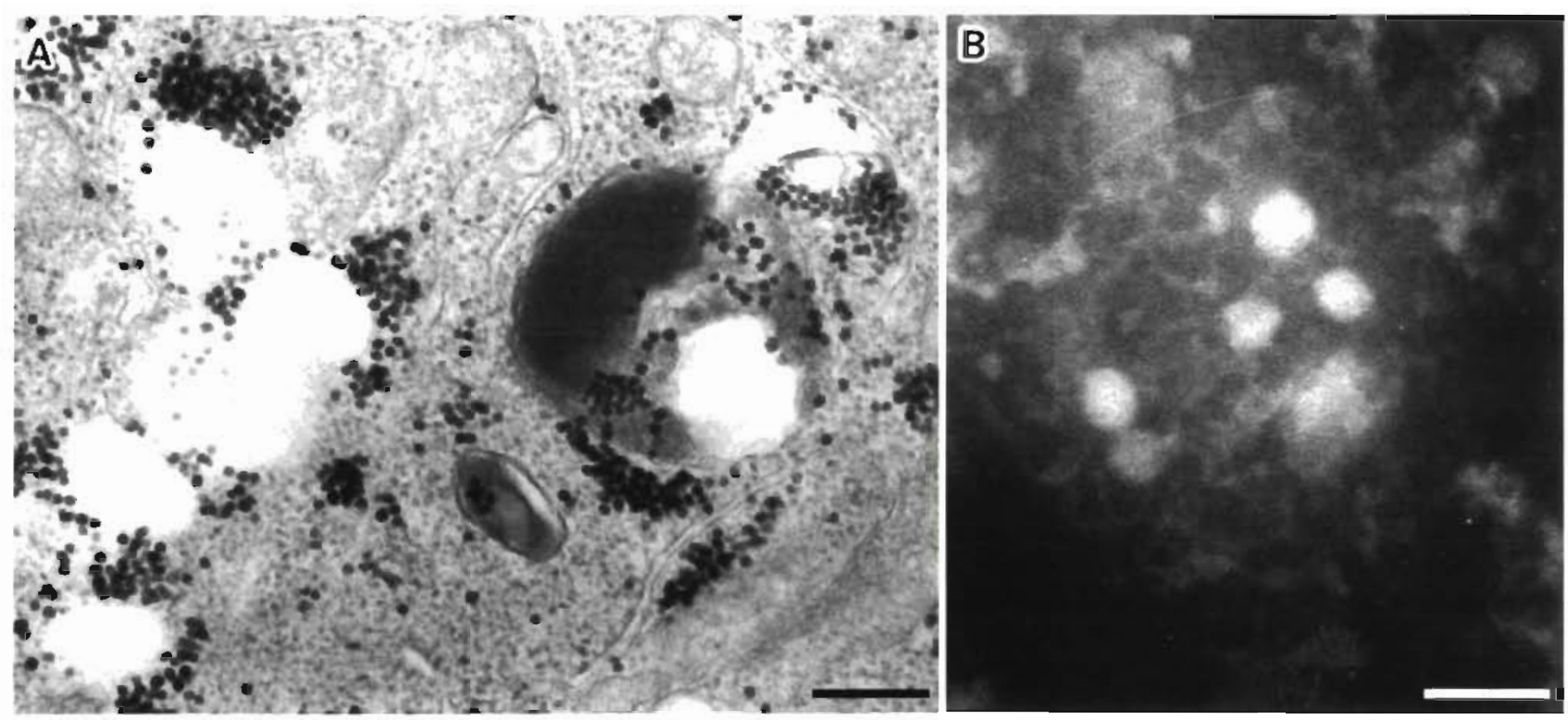

Fig. 6. Pinctada fucata martensii. (A) Electron micrograph of an infected EK-1 cell. Many virions multiplied in the cytoplasm showing vacuolization. The size and shape of virus particles are the same as those inside necrotized muscle fibers shown in Fig. 5D. Scale bar $=200 \mathrm{~nm}$. (B) Negatively stained virus particles which were obtained from the culture medium of infected EK-1 cells. $2 \%$ phosphotungstic acid stain. Scale bar $=60 \mathrm{~nm}$ 


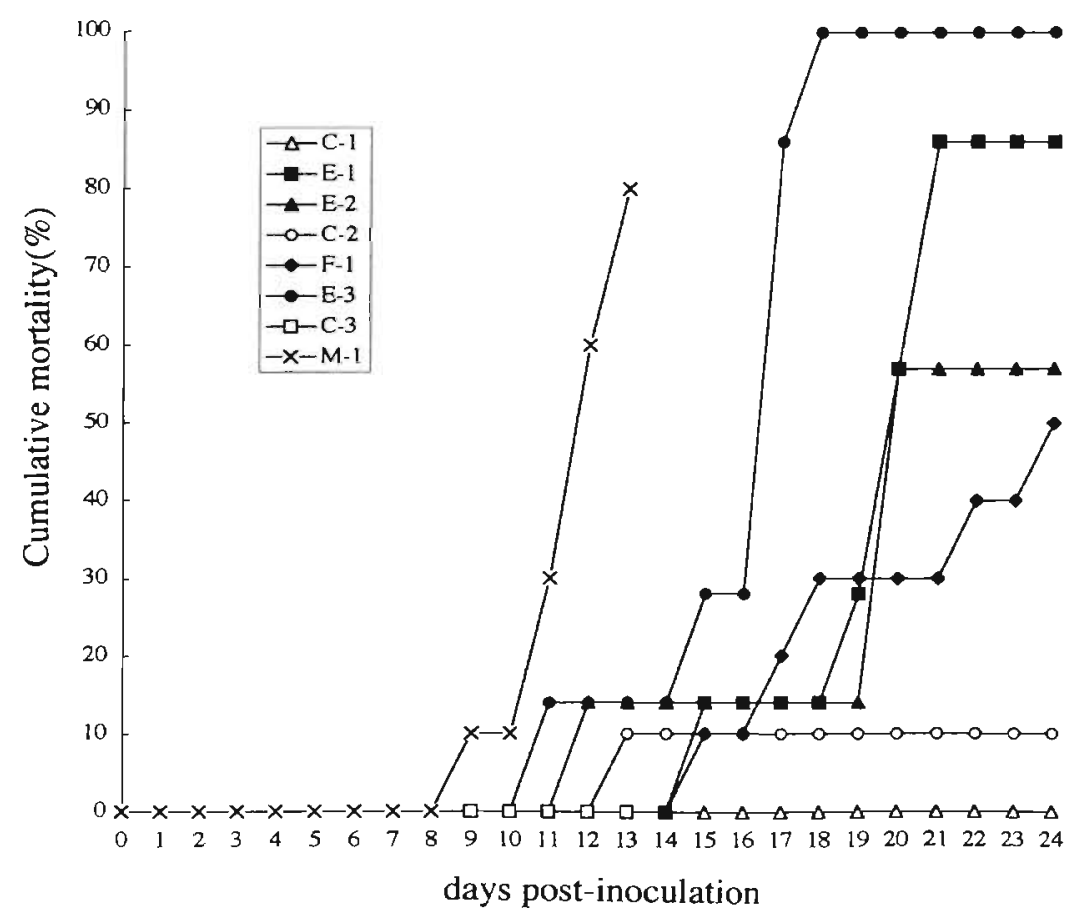

Fig. 7 Pinctada fucata martensii. Mortality graph of experimentally infected akoya oysters. Each group contained 7 to 10 oysters. Group (dead \& moribund/ treated, days of experimental period): C-1(0/7, $24 \mathrm{~d}), \mathrm{E}-1(6 / 7,24 \mathrm{~d}), \mathrm{E}-2(4 / 7,24 \mathrm{~d})$, C-2(1/10, 24 d), F-1(5/10, 24 d), E-3(7/7, 24 d), C-3(0/10, 13 d), M-1 $(8 / 10,13$ d) ing valves and exchange of the seawater inside the pallial cavity. Therefore, these functional disturbances could be expected to inhibit feeding and respiratory activities. Histological examinations of the digestive caeca of oysters in the control groups in the infectivity experiments which were not fed for more than $20 \mathrm{~d}$ revealed the tubular epithelia showing signs of atrophy which resembled those of diseased oysters in the natural outbreak. This suggested that the diseased oysters underwent longterm suspension of digestive activity. Moreover, the abnormal glucose metabolism in the diseased oysters was an important change. The decrease in glycogen in the muscle fibers and NS cells was remarkable in affected oysters in both the natural outbreak and the infectivity experiments. Compared with the controls, inoculated oysters died earlier, but reduction of nutrients, especially glycogen, was obvious and remarkable. Why did such an abnormal depletion of glycogen occur? The fast alone was

adductor and heart. These facts indicated that this virus was the cause of the mass mortality in cultured akoya oysters. Although virus-like particles were found in golden-lipped pearl oysters Pinctada maxima (Pass et al. 1988, Norton et al. 1993), this virus morphologically resembled virus-like particles (VLPS) found in New Zealand scallops Pecten novaezelandiae (Hine \& Wesney 1997). However, there were differences in the host cells, situation of multiplication and pathological signs of the 2 viruses. There have been no reports of any other bivalve viruses that resemble this virus. We are now attempting to genetically classify this virus. Until this is completed, we will refer to this virus as the 'akoya-virus'.

The akoya-virus infected muscle fibers of the adductor, and pallial, foot and gill musculatures as well as the cardiac muscle. Cardiac failure due to necrosis of the muscle would be lethal to animals and probably accounts for the mortality in the early period of the infectivity experiments. In the natural outbreak and infectivity experiment, affected oysters mostly displayed atrophy in the adductor muscle, lips of the mantle lobe and foot. In all of these tissues, muscle fibers were extensively necrotized and degenerated. Because there appeared to be disturbances in the activity of adductor muscle and lips of the mantle lobe in these oysters, this muscular damage must inhibit the open- clearly not the cause because the control did not show such a severe reduction of nutrients. It was assumed that the akoya-virus altered host glucose metabolism. Muscular activity largely depends on the ATP (adenosine triphosphate) that is generated by glycolysis. This means that the affected muscle fibers reduce activity, which was suggested by a marked decrease of glycogen granules in the sarcoplasm and by data indicating decreased ATP of the adductor muscle (Miyazaki, Nozawa \& Kobayashi unpubl. data). Based on the above facts, diseased akoya oysters died from a combination of functional disturbances of the systemic musculature, starvation and cardiac failure. EM revealed the production of an electron-dense substance surrounding inclusion bodies that contained virions. The production of this substance might be related to the yellow to brown coloration of affected muscle fibers, although further study of this subject is needed, because muscular tissue did not display any pigment in the histological examinations.

Based on the results obtained in this study, we propose that the akoya-virus is responsible for the mass mortality which occurred in the natural outbreak. Moreover, the juveniles were carriers of akoya-virus in winter. In the following summer, juvenile carriers grew into mother oysters and became victims because of the activation of harbored virus at an optimum water 

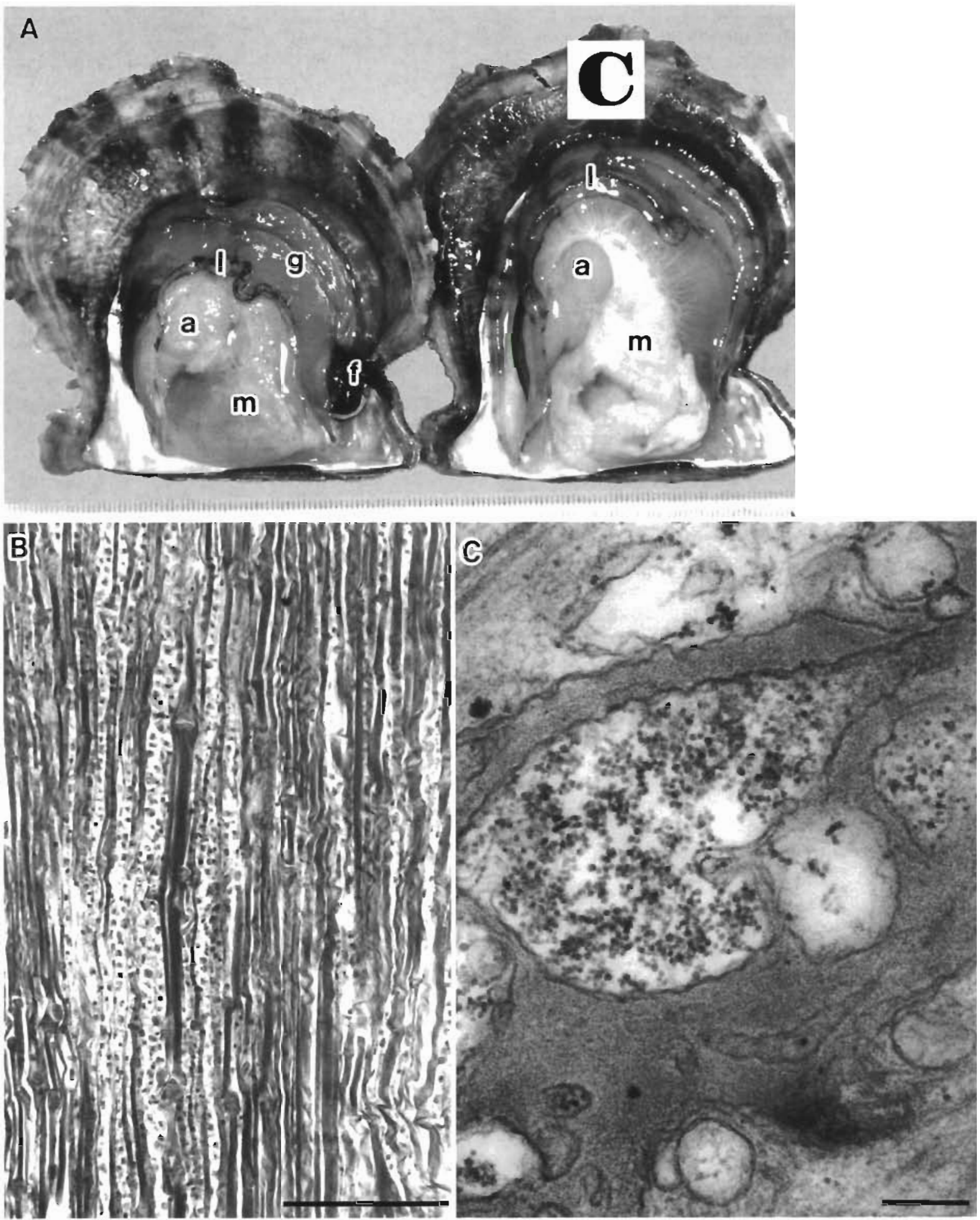

Fig. 8. Pinctada fucata martensii. (A) Dissected view of moribund (left) and control (C, right) oysters in the infectivity experiment. The moribund oyster has atrophied mantle lobe lips (l), an atrophied adductor muscle (a) and an atrophied body which is covered by the transparent mantle lobe (m). (f) Foot. (g) Gill. (B) Adductor muscle of a moribund oyster. Infected muscle fibers are extensively necrotized and accompanied by hemocyte infiltration as was the case in the natural outbreak. Azan. Scale bar $=100 \mu m$. (C) Electron micrograph of a markedly necrotized muscle fiber in the adductor muscle of an experimentally diseased oyster. Virions multiply in membranous inclusion bodies that are surrounded with electron-dense matter in the vacuolized sarcoplasm. Virus particles are the same as those in the natural outbreak. Scale bar $=300 \mathrm{~nm}$ 
temperature above $25^{\circ} \mathrm{C}$. These victims spread the akoya-virus, which caused the horizontal dissemination which resulted in mass mortalities. In recent years, millions of Chinese pearl oysters Pinctada fucata ssp. have been transported without official quarantine to Japan from Hainan Island, China. We isolated a virus that closely resembled the akoya-virus from Chinese pearl oysters (Miyazaki, Nozawa \& Kobayashi unpubl. data). We speculate that the akoya-virus came with the Chinese pearl oysters although a genetic investigation is needed in further studies.

Acknowledgements. This study was supported by grants from the Japan Pearl Promotion Society and the Ehime Allied Society of Fishery Cooperative. We also express our great thanks to Dr M. Tange for supporting this study.

Editorial responsibility: Albert Sparks,

Seattle, Washington, USA

\section{LITERATURE CITED}

Chen SW, Ueno Y, Kou GH (1982) A cell line derived from Japanese eel (Anguilla japonica) kidney. Proc Natl Sci Counc Repub China 6:93-100

Hine PM, Wesney B (1997) Virus-like particles associated with cytopathology in the digestive gland epithelium of scallops Pecten novaezelandiae and toheroa Paphies ventricosum. Dis Aquat Org 29:197-204

Norton JH, Shepherd MA, Prior HC (1993) Papovavirus-like infection of golden-lipped pearl oyster, Pinctada maxima, from the Torres Strait, Australia. J Invertebr Pathol 62: $198-200$

Pass DA, Perkins FP, Dybdahl R (1988) Virus-like particles in digestive gland of pearl oyster (Pinctada maxima). J Invertebr Pathol 51:166-167

Tomasec J, Fijan N (1971) Virusne bolestiriba (viral diseases of fish). Final report on research under a part of project 6n/1966. Zagreb

Submitted: June 17, 1998; Accepted: November 6, 1998 Proofs received from author(s): May 31, 1999 